\title{
Coeficientes técnicos de produção da priprioca (Cyperus articulatus L.) em sistema orgânico, na região de Belém (PA).
}

CASTELLANI, D.C. ${ }^{*}$; DOMENICO, C.I. ${ }^{1}$ RONCOLETTA, L.M.A. ${ }^{2}$; SILVA, A.C. ${ }^{1}$; TOZAKI R.M. ${ }^{1}$; OLIVEIRA, D.H. ${ }^{1}$. ${ }^{1}$ Natura Inovação e Tecnologia de Produtos Ltda., Diretoria de Ciência e Tecnologia, Laboratório de Bioagricultura - Tecnologias Sustentáveis. Rodovia Anhanguera Km 30.5 s/no , Bloco A, 4o andar, Cajamar (SP), 07750-000, Brasil; 'deboracastellani@natura.net. ${ }^{2}$ Beraca Health \& Personal Care. Área de Relacionamento com Comunidades. Rodovia BR $316 \mathrm{Km} 8$ s/no Q 3 L3, Ananindeua (PA), 67030-000, Brasil.

\begin{abstract}
RESUMO: Foram elaborados os coeficientes técnicos de produção de priprioca (Cyperus articulatus) em três áreas fornecedoras parceiras da Natura, situadas na região do entorno de Belém, Amazônia Oriental. Para elaboração dos coeficientes técnicos de produção de priprioca, os itens de custo e as atividades que compreendem o cultivo, a colheita e o beneficiamento foram levantados e classificados em: Insumos; Serviços; Equipamentos; e Outros. O detalhamento destas atividades e o valor dos itens foram obtidos e construídos in loco, juntamente com os agricultores. As informações utilizadas neste trabalho consideraram a produção de 1 tonelada de raiz de priprioca, cultivadas anualmente em sete canteiros de $60 \mathrm{~m}^{2}(1,2 \mathrm{~m}$ largura $\times 50 \mathrm{~m}$ comprimento), espaçamento de $0,20 \times 0,20 \mathrm{~m}$, em sistema orgânico com rendimento médio de $2,5 \mathrm{~kg} \mathrm{~m}^{2-1}$. Os resultados descrevem os materiais consumidos, o tempo de mão-de-obra para realização das operações e os custos, baseados na realidade local. Conclui-se com este trabalho que a elaboração do coeficiente técnico de produção auxilia o agricultor a estimar o custo de produção de uma determinada matéria prima e evidencia as atividades que podem contribuir no lucro como, por exemplo, as boas práticas de produção.
\end{abstract}

Palavras-chave: Cyperus articulatus, Plantas aromáticas, óleo essencial, biodiversidade, Amazônia.

\begin{abstract}
Technical coefficients of priprioca production (Cyperus articulatus L.) in organic system at the region of Belém (PA). Were prepared the technical coefficients of priprioca (Cyperus articulatus) production in three areas suppliers partner of Natura, situated around Belem, Eastern Amazon. For preparation of technical coefficients of priprioca production, the cost items and activities that comprise the growing, harvesting and processing were collected and classified as: Inputs, Services, Equipment, and Others. The details of these activities and the value of the items were obtained and constructed in situ, together with the farmers. Information used in this study considered the production of one tonne of priprioca root cultivated annually in seven plots of $60 \mathrm{~m}^{2}(1,2 \mathrm{~m}$ wide $\times 50 \mathrm{~m}$ length) $0,20 \times 0,20 \mathrm{~m}$, in an organic system average yield of $2,5 \mathrm{~kg} \mathrm{~m}^{2-1}$. The results describe the materials consumed, the time of manpower to carry out the operations and costs, based on local realities. Were conclude with this work that the preparation of the technical coefficient production helps farmers to estimate the cost of production and highlights the activities that can contribute to profit, for example, good manufacturing practices.
\end{abstract}

Key words: Cyperus articulatus, Aromatic plants, essencial oils, biodiversity, Amazon.

\section{INTRODUÇÃO}

Várias espécies de Cyperus (Família Cyperaceae) foram estudadas, em diversos países, quanto à presença e composição dos óleos essenciais presentes em suas raízes, dentre elas Cyperus rotundus, $C$. tuberosus, $C$. giganteum, $C$. odorata, C. prolixus e $C$. articulatus (Sonwa \& König,
2001; Olaware et al. 2006; Zoghbi et al., 2008; Oladipupo \& Oyedeji, 2009).

A priprioca (Cyperus articulatus) é uma espécie do Brasil cultivada por comunidades rurais do Pará e comercializada como planta aromática. Geralmente são cultivadas em quintais, para uso 
próprio, e em sistema de consórcio com outras culturas, para comercialização (Zoghbi et al., 2005).

Das plantas aromáticas se extraem os óleos essenciais, descritos como substâncias voláteis, orgânicas, odoríferas, de grande importância para a indústria de perfumaria, que tem interesse crescente em novos aromas de origem natural (Martinazzo, 2007). O óleo essencial de priprioca (Cyperus articulatus) foi estudado por muitos autores (Couchman, 1964; Nyasse et al., 1988; Zoghbi, 2006; Mattoso, 2005) e seu aroma tem despertado interesse da indústria de cosméticos.

O óleo essencial de priprioca é utilizado pela Natura Cosméticos como ingrediente natural de diversos produtos, destacando-se a Linha Ekos Priprioca. Esta fragrância celebra de forma única e inovadora o caminho olfativo floral verde; seu perfume é marcante e inusitado, sendo uma matéria-prima de muito valor para os perfumistas devido à sua originalidade (Natura Ekos, 2011).

O plantio de priprioca deve ser realizado no início da época chuvosa (janeiro e fevereiro) - estação do inverno (Nicole et al., 2006) e a colheita pode ser realizada após 9 meses do plantio, no final da estação seca (novembro) - estação do verão.

No cálculo do custo de produção de uma determinada cultura deve constar como informação básica a combinação de insumos, de serviços e de máquinas e implementos utilizados ao longo do processo produtivo. Esta combinação é conhecida como "pacote tecnológico" e indica a quantidade de cada item em particular, por unidade de área, que resulta num determinado nível de produtividade. Essas quantidades mencionadas, referidas à unidade de área (hectare) são denominadas de coeficientes técnicos de produção, podendo ser expressas em tonelada, quilograma ou litro (corretivos, fertilizantes, sementes e agrotóxicos), em horas (máquinas e equipamentos) e em dia de trabalho (Conab, 2010).

Andrião (2008) mostraram que a definição do custo de produção tem se tornado uma ferramenta de controle e de decisão, auxiliando na identificação e mitigação dos fatores que influenciam diretamente ou indiretamente a atividade agrícola. Martin (1994) ainda afirma que a utilização de estimativas de custo de produção permite analisar a eficiência da produção e de seus processos específicos, os quais indicam o sucesso de determinado produtor no seu esforço de produzir.

Este trabalho teve como objetivo elaborar os coeficientes técnicos de produção da priprioca (Cyperus articulatus L.) em sistema orgânico, junto aos fornecedores de ingredientes vegetais da Natura.

\section{MATERIAL E MÉTODO}

O estudo foi realizado em três áreas produtoras de priprioca (Cyperus articulatus), na região do entorno de Belém, sendo fornecedores parceiros da Empresa Natura Cosméticos desde 2003. No levantamento de dados contou se com 15 informantes diretos além do histórico de produção de 47 produtores pertencentes aos seguintes empreendimentos comunitários: (1) Associação dos Moradores de Boa Vista do Acará - Acará (PA); (2) Associação dos Produtores Rurais de Campo Limpo - Santo Antônio do Tauá (PA) e (3) Movimento das Mulheres das Ilhas de Belém - Ilha de Cotijuba em Belém (PA).

Para elaboração dos coeficientes técnicos de produção de priprioca, os itens de custo e as atividades que compreendem o cultivo, a colheita e 0 beneficiamento foram levantados e classificados em:

- Insumos: materiais consumidos no processo de produção da matéria prima;

- Serviços: atividades realizadas durante a produção da matéria prima e

- Equipamentos: utensílios necessários para realização das atividades e controle de qualidade da matéria prima.

De modo geral, a produção de priprioca se desenvolve em etapas distintas que incluem preparo das mudas, preparo do solo, plantio, tratos culturais e colheita. Assim, os insumos, serviços e equipamentos são incorporados no sistema em diferentes momentos, ao longo do processo produtivo. $O$ detalhamento destas atividades e o valor dos itens foram obtidos e construídos in loco, de maneira participativa. As reuniões e visitas técnicas foram realizadas durante o ano de 2009 e 2010 . Os dados foram sistematizados e validados pelos agricultores dos três grupos de fornecedores de priprioca.

As informações utilizadas neste trabalho consideraram a produção de 1 tonelada de raiz de priprioca em uma área de $420 \mathrm{~m}^{2}$ (7 canteiros), em sistema orgânico. A priprioca é cultivada em canteiros $\left(60 \mathrm{~m}^{2}\right)$ no espaçamento de $0,20 \mathrm{~m} \times 0,20 \mathrm{~m}$. Para a elaboração dos coeficientes técnicos de produção de priprioca optou-se por considerar a produtividade de $2,5 \mathrm{~kg} \mathrm{~m}^{2-1}$ assumindo a diversidade de condições locais e de práticas adotadas, porem de acordo com o levantamento de dados a produtividade pode chegar a $8 \mathrm{~kg} \mathrm{~m}^{2-1}$. Na determinação do custo de insumos e serviços foi considerado o ano agrícola de 2010.

\section{RESULTADO E DISCUSSÃO}

A priprioca (Cyperus articulatus) é uma planta perene, de reprodução predominantemente assexuada, viabilizada sob o ponto de vista agronômico pela divisão de tubérculos. A reprodução de sementes é pouco significativa, pois menos de $5 \%$ das sementes formadas são viáveis (Silva et al, 2008). 
A priprioca tem sido conduzida como cultura anual e as práticas de produção variam entre os agricultores, principalmente, no que diz respeito ao numero de adubações e capinas. Para o cultivo de priprioca é preciso inicialmente limpar a área, posteriormente preparar os canteiros, realizar uma adubação antes do plantio, fazer a divisão dos tubérculos, também denominado por eles de "batata" ou "semente", cortar/picar a planta que servirá como cobertura morta no canteiro, para então realizar o plantio e se necessário, replantio de mudas.

Geralmente, os produtores reservam pequenas parcelas dos canteiros como fonte de material de propagação. Entretanto, recomenda-se manter um canteiro com plantas vigorosas para a produção de novas mudas. As mudas devem ser plantadas com uma parte do tubérculo fora da terra, de forma a expor a brotação. Se o plantio for seguido por chuva, os tubérculos brotam com facilidade. No plantio de priprioca, os canteiros são preparados na medida de 1,2 $\mathrm{m}$ de largura por comprimentos variáveis, sob luz plena pois, a priprioca não tolera sombreamento (Figura 1).

A Tabela 1 apresenta os coeficientes técnicos de produção de priprioca (Cyperus articulatus), em sistema orgânico, na região do entorno de Belém (PA).

Nas operações que refletem o sistema de cultivo, foram descritos os materiais consumidos e quantidade de mão-de-obra para realização das operações. O custo dos insumos, serviços e equipamentos baseou-se na realidade local dos três grupos de fornecedores: Boa Vista, Campo Limpo e Cotijuba. A mão-de-obra é familiar porem em geral, no cálculo dos coeficientes técnicos considera-se a possibilidade de contratação de trabalha temporário entendendo-se como aquele que é remunerado por dia de serviço na execução de tarefas que não exigem maiores qualificações (Conab, 2010).

Após 30-40 dias do plantio da priprioca realiza-se a primeira adubação de cobertura juntamente com a primeira capina, a fim de controlar as plantas espontâneas. Este tempo para a primeira capina é possível quando há grande quantidade de cobertura morta no canteiro, do contrário a capina ocorre após 10 dias do plantio. A prática da cobertura morta ainda não é adotada por todos os produtores, mas entre aqueles que a utilizam, é consenso que o trabalho de capina reduz consideravelmente.

Carvalho et al. (2005) estudaram cobertura do solo no cultivo de alface e também observaram que o controle de plantas daninhas foi eficiente nos tratamentos em que se empregou cobertura morta, enquanto na testemunha a densidade de plantas espontânea foi muito superior. A mesma conclusão é encontrada no estudo de Resende et al. (2005) para o cultivo de cenoura pois, com o uso de maravalha (raspa de madeira) houve menor incidência de plantas espontânea. Essa pratica de manejo é considerada um dos processos chave para redução da mão de obra, manutenção da estrutura e fertilidade dos solos tropicais (Santos et al., 2008).

A segunda adubação de cobertura ocorre aos 50-60 dias após o plantio; a aplicação de biofertilizante

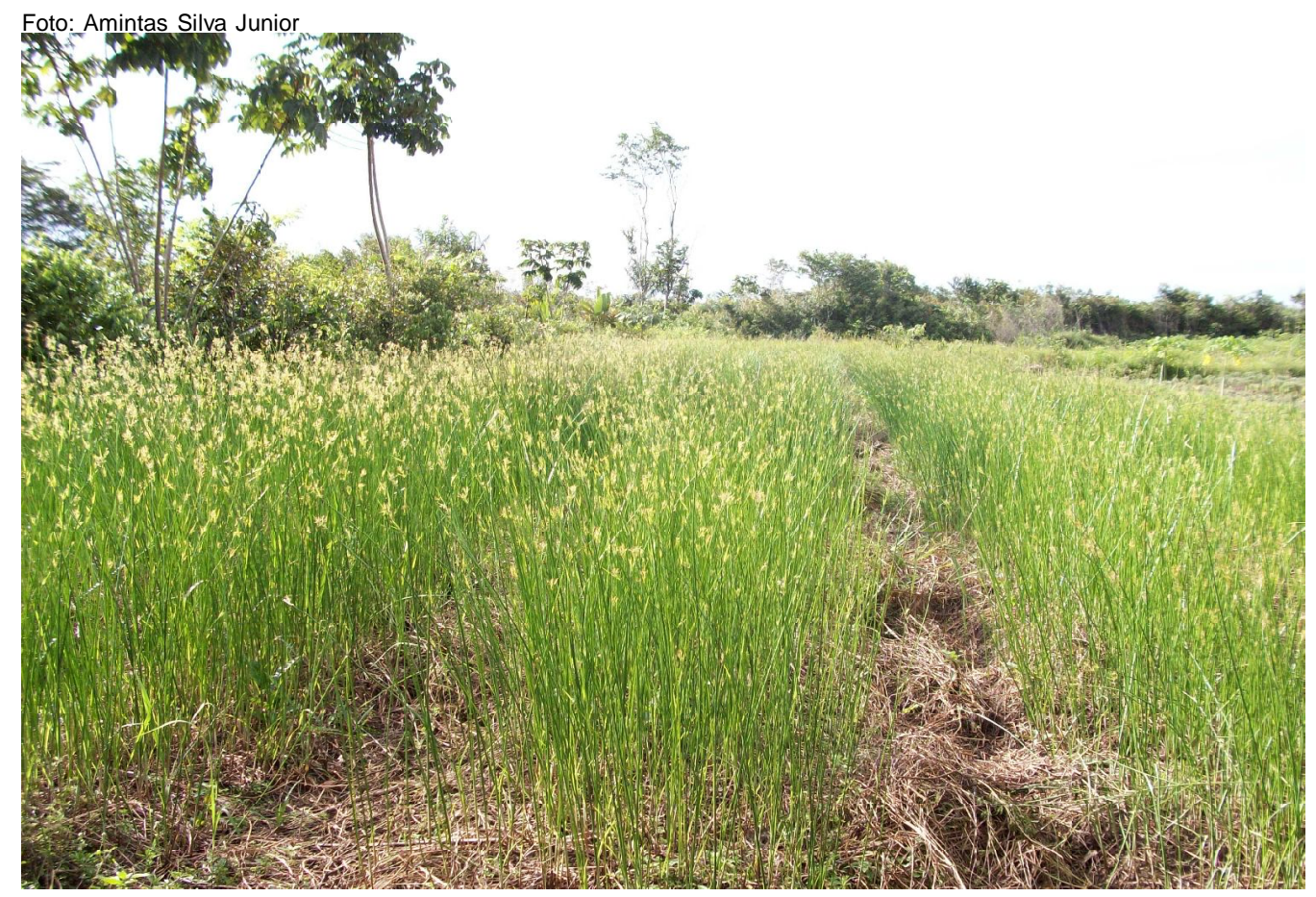

FIGURA 1. Produção orgânica de priprioca (Cyperus articulatus) em Santo Antonio do Tauá (PA) (Production of organic priprioca (Cyperus articulatus) in Santo Antonio do Tauá - PA). 
TABELA 1. Coeficientes técnicos para produção de uma tonelada de raiz de priprioca (Cyperus articulatus) na região de Belém do Pará, em 2010 (Technical coefficients to produce a tonne of priprioca (Cyperus articulatus) root in the region of Belem - PA, 2010).

\begin{tabular}{|c|c|c|c|c|}
\hline Descrição & Unid. & Quantidade & $\begin{array}{l}\text { Valor unitário } \\
(\mathrm{R} \$)\end{array}$ & Valor total $(\mathrm{R} \$)$ \\
\hline \multicolumn{5}{|l|}{ Insumos } \\
\hline Análise de solo & unid & 1,0 & 10,00 & 10,00 \\
\hline Adubação de base & ton & 1,0 & 200,00 & 200,00 \\
\hline Adubação de cobertura & ton & 2,0 & 200,00 & 400,00 \\
\hline Controle Fitossanitário & ton & 0,5 & 100,00 & 50,00 \\
\hline Subtotal 1 & & & & 660,00 \\
\hline \multicolumn{5}{|l|}{ Serviços } \\
\hline Preparo da área & $\mathrm{D} / \mathrm{H}$ & 3,5 & 25,00 & 87,50 \\
\hline Preparo do canteiro & $\mathrm{D} / \mathrm{H}$ & 3,0 & 25,00 & 75,00 \\
\hline Divisão de tubérculos & $\mathrm{D} / \mathrm{H}$ & 7,0 & 25,00 & 175,00 \\
\hline Plantio e replantio & $\mathrm{D} / \mathrm{H}$ & 5,0 & 25,00 & 125,00 \\
\hline Manejo da adubação verde & $\mathrm{D} / \mathrm{H}$ & 3,0 & 25,00 & 75,00 \\
\hline Capina/Roçada & $\mathrm{D} / \mathrm{H}$ & 35,0 & 25,00 & 875,00 \\
\hline Aplicação de adubo & $\mathrm{D} / \mathrm{H}$ & 1,5 & 25,00 & 37,50 \\
\hline Cobertura morta & $\mathrm{D} / \mathrm{H}$ & 3,5 & 25,00 & 87,50 \\
\hline Manutenção das matrizes & $\mathrm{D} / \mathrm{H}$ & 2,0 & 25,00 & 50,00 \\
\hline Aplicação de biofertilizante & $\mathrm{D} / \mathrm{H}$ & 3,0 & 25,00 & 75,00 \\
\hline Colheita e Beneficiamento & $\mathrm{D} / \mathrm{H}$ & 25,0 & 25,00 & 625,00 \\
\hline Pesagem & $\mathrm{D} / \mathrm{H}$ & 0,5 & 25,00 & 12,50 \\
\hline Subtotal 2 & & & & $2.300,00$ \\
\hline \multicolumn{5}{|l|}{ Equipamentos } \\
\hline Ferramenta para manejo ${ }^{\star *}$ & unid & 1,0 & 2,00 & 2,00 \\
\hline Equipamento de proteção** & unid & 1,0 & 3,00 & 3,00 \\
\hline Equipamento de colheita** & unid & 1,0 & 1,00 & 1,00 \\
\hline Saco de colheita & unid & 20,0 & 0,75 & 15,00 \\
\hline Lona plástica & $\mathrm{m}$ & 10,0 & 1,50 & 15,00 \\
\hline Subtotal 3 & & & & 36,00 \\
\hline Total $(1+2+3)=$ & & & & 2996,00 \\
\hline \multicolumn{5}{|l|}{ Despesas extras (10\%) } \\
\hline Outras despesas & & & & 299,60 \\
\hline Total Geral (R\$/ton) & & & & $3.295,60$ \\
\hline Custo de produção (R\$ & & & & 3,30 \\
\hline
\end{tabular}

${ }^{*}$ Rateio do custo

é realizada duas vezes ao ano. A torta de andiroba, resíduo da extração de óleo das sementes de andiroba (Garapa guianensis), é utilizada no controle de paquinha (Neocurtilla hexadactyla), quando necessário. O número de capinas varia de três a seis durante os doze meses de cultivo da priprioca, com isso os agricultores consideraram quatro capinas uma boa média, sendo que a última capina coincide com o corte raso da planta, que acontece antes da colheita.

A colheita das raízes de priprioca é feita com auxílio da enxada (ou vara alavanca), logo após são batidas para retirada do excesso de terra e lavadas. Posteriormente ocorre à retirada das radículas, 
também chamadas de "barba" ou "estopa". A matéria prima é então ensacada e no mesmo dia é transportada para a indústria de extração do óleo essencial.

A definição dos coeficientes técnicos da cultura de priprioca considerou a adoção das práticas pelos agricultores locais e o potencial produtivo associado.

O custo de produção de priprioca (Cyperus articulatus), com a incorporação de práticas agroecológicas, foi estimado no ano de $2010 \mathrm{em} R \$$ $3,30 / \mathrm{kg}$ de matéria-prima. De acordo com Cunha (2006) a alta produtividade da priprioca traz vantagens para o pequeno produtor.

As despesas com infraestrutura e consultorias relacionadas à assistência técnica e a certificação orgânica (Selo IBD) foram contabilizadas como investimentos nos parceiros rurais.

De acordo com Nicole et al. (2006) o custo operacional para produção de tubérculos de priprioca (Cyperus articulatus) foi $R \$ 1,30 / \mathrm{kg}$, sendo uma atividade altamente intensiva na demanda de mãode-obra ( $82 \%$ do custo de produção). Segundo Cunha (2006), o manejo realizado do plantio à colheita da priprioca é manual e envolve pequeno contingente de mão-de-obra. Os tratos culturais restringem se basicamente a capinas que exigem a participação efetiva da mão-de-obra.

A fim de estimular as boas práticas de produção nas áreas fornecedoras e garantir a qualidade da matéria prima, foi incluído nos coeficientes técnicos: (1) análise de solo da área precedente ao cultivo, visando orientar a correção do solo e adubação, (2) o emprego de adubação verde, a fim de melhorar a fertilidade do solo e gerar biomassa para a cobertura morta, além atuar como quebra vento no caso da adoção de espécies arbustivas e arbóreas, (3) o aumento da quantidade de cobertura morta, visando principalmente diminuir o número de capinas, e (4) a utilização de equipamentos de segurança durante todo o processo de produção.

A priprioca é considerada uma planta rústica e apresenta tolerância a solos ácidos, típicos na Amazônia. Contudo de acordo com Cunha (2006), no cultivo de priprioca, a produção de óleo essencial pode aumentar com a adição de calcário e aplicação de cama aviária na cultura. A cama aviária apresentase como melhor fonte de adubo orgânico quando comparada à torta de mamona e ao esterco de gado.

Diversos materiais são utilizados pelos produtores na adubação da priprioca, entre eles a cama de frango, o esterco de gado e casca de mandioca, além das tortas (resíduos) de andiroba e cupuaçu. É importante que todos os materiais estejam devidamente curtidos ou compostados.

Segundo Falesi et al. (1980) os solos representativos do Estado do Pará são ácidos, com $\mathrm{pH}$ variando entre 4,0 e 5,5 e fertilidade natural muito baixa, em função dos baixos teores de nutrientes essenciais às culturas. Portanto, como medidas preventivas para o desenvolvimento adequado às atividades agropecuárias nesses solos, devem ser efetuadas práticas de calagem e de fertilização dos solos a fim de eliminar efeitos deletérios ao desenvolvimento do sistema radicular causado pelo alumínio em excesso e elevar os teores dos nutrientes essenciais às plantas a um nível satisfatório.

Dadas às peculiaridades da atividade agrícola, os referidos coeficientes são influenciados diretamente pela diversidade de condições ambientais de clima, de fertilidade, de tipos e topografia do solo, dentre outros, que moldam, na prática, uma grande variedade de padrões tecnológicos de produção. Assim, para tornar possível o estabelecimento de coeficientes técnicos e superar os problemas da extrema diversidade existente, faz-se necessária a aceitação de alguns padrões genéricos que sejam representativos do conjunto de tecnologias adotadas pelos produtores das diferentes regiões do País, desde que guardem certa consistência entre eles (Conab, 2010).

Segundo Miqueletto et al. (2000) os resultados do trabalho devem ser considerados com atenção, pois em qualquer atividade agrícola, a produtividade pode variar de acordo com o sistema de cultivo e o gerenciamento adotado.

Segundo Cunha (2006), o cultivo de priprioca constitui-se um sistema de produção alternativo, economicamente viável, com uma perspectiva de mercado altamente promissor. Por sua tolerância à acidez dos solos do Estado do Pará tem potencial para plantio em áreas degradadas, diminuindo assim a demanda pela abertura de novas áreas. Ainda, contribui para fixação do agricultor no campo, diversificação da propriedade rural e para geração de renda familiar.

O manejo da priprioca deve incorporar as boas práticas de produção visando melhorias na produtividade, redução de mão de obra e qualidade no trabalho. É importante também que os agricultores tenham uma visão ampla da cadeia de produção visando mais benefícios econômicos, sociais e ambientais. De acordo Michellon e Sacoman (2011) o manejo pode aumentar ou diminuir o grau de instabilidade do sistema produtivo. Assim, um sistema de custo completo deve refletir sua importância como ferramenta para gestão de qualquer empreendimento, especialmente na agropecuária.

A agricultura ecológica considera a interação com o ser humano, cujas ações estão pautadas na sua cultura, hábitos e tradições. Segundo Altieri (1989) está implícita também a idéia de que por meio da compreensão desses processos e relações, os

Rev. Bras. Pl. Med., Botucatu, v.13, especial, p.606-611, 2011. 
agroecossistemas podem ser manipulados para produzir melhor, com menos insumos externos, menos impactos negativos ambientais e sociais e mais sustentabilidade.

A construção participativa foi essencial para elaboração dos coeficientes técnicos de produção de priprioca, cultivada pelos agricultores familiares do entorno de Belém (PA). Na elaboração do custo de produção as boas práticas devem ser incorporadas em todas as etapas da cadeia produtiva garantindo a produção sustentável.

\section{AGRADECIMENTO}

Aos produtores de priprioca das comunidades de Campo Limpo, Boa Vista e Cotijuba.

\section{REFERÊNCIA}

ALTIERI, M. A. Agroecologia: as bases científicas da agricultura alternativa.

Trad. de Patrícia Vaz. Rio de Janeiro: PTA/FASE, 1989. 240p.

ANDRIÃO, M.A. Desenvolvimento de planilha para cálculo de custo de produção de plantas medicinais: Baccharis trimera (Less.) DC. cultivada em propriedade rural do nordeste paulista. In: SIMPÓSIO DE PLANTAS MEDICINAIS DO BRASIL, 20, 2008, São Paulo. Resumos... São Paulo. 2008. p. 16 - 26.

CONAB - Companhia Nacional de Abastecimento. Custo de produção agrícola: a metodologia da Conab. Brasília: Conab, 2010. 60 p.

COUCHMAN, F.M.; PINDER, A.R.; BROMHAM, N.H. Studies on the essencial oil of Cyperus articulatus $\mathrm{L}$. Tetrahedron, v. 20, n.9, p. 2037 - 2045, 1964.

CUNHA, D.C. Produção de tubérculos e de óleo essencial de priprioca (Cyperus articulatus L.), em função da adubação orgânica e calagem. 2006. 80 p. Dissertação (Mestrado em Agronomia - Solos e Nutrição de Plantas) - Departamento de Agronomia, UFRA, Belém.

FALESI, I. C.; BAENA, ; DUTRA, S. Conseqüência da exploração agropecuária

sobre as condições físicas e químicas dos solos das micro-regiões do

Nordeste Paraense. Belém: EMBRAPA-CPATU, 1980. 49p (Boletim de pesquisa n.14).

MARTIN, N.B.. Custos: sistema de custos de produção agrícola. Informações econômicas, v. 24, n. 9, p.6-26, 1994.

MIQUELETTO, DF; CARDOSO, JL; MARTIN, NB. Avaliação econômica da produção comercial de uva niagara: uma aplicação do software CUSTAGRI 1.0. Informações Econômicas, v. 30, n. 11, p. 7-15, 2000.

MATTOSO, E. Estudo de fragrâncias amadeiradas da Amazônia. 2005. 143 p. Dissertação (Mestrado - Área de concentração em Química Orgânica ) - Instituto de Química, UNICAMP, Campinas.

MICHELLON, E.; SACOMAN, A. Gestão econômica das atividades agropecuárias: custo de produção, análises de sensibilidade e de investimento. Disponível em: http:/ /www.sober.org.br/palestra/6/807.pdf. Acesso em: 13/05/ 2011.

NICOLI, C.M.L.; HOMMA, A.K.O.; MATOS, G.B.de; MENEZES, A.J.E.A.de. Aproveitamento da Biodiversidade Amazônica: o caso da priprioca. Belém, PA: Embrapa Amazônia Oriental, Documentos 256, 2006. $25 \mathrm{p}$.

NATURA EKOS. Disponível em: <http:// www.naturaekos.com.br/biodiversidade/priprioca>.

Acesso em: 20/08/2011.

NYASSE, B.; GHOGOMU TIH, R.; SONDENGAM, B.L.; MARTIN, M.T.; BODO, B. Mandassidione and other sesquiterpenic ketones from Cyperus articulatus. Phytochemistry, v. 27, n. 10, p. 3319-3321, 1988.

OLADIPUPO, A.L.; OYEDEJI, A.O. Chemical composition of the essential oils of Cyperus rotundus L. from South Africa. Molecules, v. 14, p. $2909-2917,2009$.

OLAWORE, N.O.; USMAN, L.A.; OGUNWANDE, I.A.; ADELEKE, K.A. Constituintes of rhizome essential oils of two types of Cyperus articulatus L. grown in Nigeria. Journal of Essential Oil Research, v.18, p. 604-06, 2006. RESENDE, F.V.; SOUZA, L.S.de; OLIVEIRA, P.S.R.de; GUALBERTO, R. Uso de cobertura morta vegetal no controle da umidade e temperatura do solo, na incidência de plantas invasoras e na produção da cenoura em cultivo de verão. Ciência e agrotecnologia. Lavras, v. 29, n. 1, p. 100-105. 2005.

SANTOS et al. Fundamentos da matéria orgânica do solo: ecossistemas tropicais e subtropicais. 2. ed. revisado e atualizado. Porto Alegre: Metrópole, 2008. $654 p$.

SILVA, Antonia Benedita da; MOTA, Milton Guilherme da Costa; SANTOS FILHO, Benedito Gomes dos; CONCEIÇÃO, Carmem Célia Costa da; DUARTE, Eleonora Brasil. Brotação de tubérculos de priprioca (Cyperus articulatus L. var. nodosus) em diferentes substratos. In: Priprioca: Um recurso aromático do Pará. Belém: MPEG; UEPA, 2008.

SONWA, M.M.; KÖNIG, W.A. Chemical study of the essential oil of Cyperus rotundus. Phytochemistry, v. 58, n. 5, p. 799-810, 2001.

ZOGHBI, M.G.B. et al. Composição química dos óleos essenciais de priprioca

(Cyperus articulatus L. e Kyllinga sp) no Estado do Pará. Disponível em:

<http://www.adaltech.com.br/evento/museugoeldi/ resumoshtm/resumos/R0935-

2.htm>. Acesso em: 26 mar. 2005.

ZOGHBI, M. G. B., ANDRADE, E. H. A., OLIVEIRA, J. et al. Yield and chemical composition of the essential oil of the stems and rhizomes of Cyperus articulatus L. cultivated in the state of Pará, Brazil. Journal of Essential Oil Research., jan/fev, 2006.

ZOGHBI, M. das G.B.; ANDRADE, E.H.A.; CARREIRA, L.M.M.; ROCHA, E.A.S. Comparison of the main components of the essential oils of "priprioca": Cyperus articulates var. articulatus L., C. articulatus var. nodosus L., C. prolixus Kunth and $C$. rotundus $\mathrm{L}$. The Journal of Essential Oil Research, v. 20, n. 1, p. 42-46, 2008. 